\title{
The Role of Life Orientation and Cognitive Regulation on Decreasing Job Stress
}

\author{
Abbas Sadeghi ${ }^{*}$, Aram Yousefi ${ }^{2}$, Zahra Khedmati² \\ ${ }^{1}$ Department of Educational Sciences, University of Guilan, Rasht, Iran \\ ${ }^{2} \mathrm{MA}$ in General Psychology, Islamic Azad University, Science and Research Branch, Rasht, Iran \\ Email:*asadeghi1394@gmail.com
}

How to cite this paper: Sadeghi, A., Yousefi, A. and Khedmati, Z. (2018) The Role of Life Orientation and Cognitive Regulation on Decreasing Job Stress. Health, 10, 268-281.

https://doi.org/10.4236/health.2018.102021

Received: January 17, 2018

Accepted: February 25, 2018

Published: February 28, 2018

Copyright (c) 2018 by authors and Scientific Research Publishing Inc. This work is licensed under the Creative Commons Attribution International License (CC BY 4.0).

http://creativecommons.org/licenses/by/4.0/

\begin{abstract}
The aim of this study is to investigate the relationship between life orientation and cognitive emotion regulation with job stress. On this basis, a sample of 100 employees working in Guilan Education Office was used and research hypotheses were examined by job stress, life orientation and cognitive emotion regulation questionnaires. The results of this study indicate that job stress has a significant relationship with life orientation $(-0.32)$, self-blame $(0.25)$, rumination $(-0.36)$, positive refocusing $(0.25)$, positive refocusing on program $(-0.21)$, positive reappraisal $(-0.28)$, catastrophizing $(-0.39)$ and other blames $(-0.25)$. Furthermore, life orientation and cognitive regulation could explain $22 \%$ variances in respondents' job stress. This finding indicates that more positive life orientation and subsequent decrease of emotion-regulation-related disorders will lead to less job stress.
\end{abstract}

\section{Keywords}

Job Stress, Cognitive Emotion Regulation, Life Orientation, Workplace

\section{Introduction}

Contemporary human life is full of stressful sources which lead to failure, stress and unpleasant experiences in life [1]. Work and life are certainly two important dimensions in any individual life [2]. Consequently, stress in life or workplace can cause numerous problems for people in their social and family relationships or even it can put individual mental and physical health at risk [1]. Stress stems directly from Latin root as to force or compulsion; laying pressure on something or oppression. This work became quickly prevalent as one of the most popular terms in last 5 decades [3].

Today, job stress is one of the most important issues in social life and it is 
considered as a serious threat for workforce health in all of the world such that International Labor Organization explicitly considered job stress is as the most known threatening cause of workers' health [4]. Stress is one of the most prevalent concepts in psychological and social research areas [5]. Dipboy et al. [6], in their all-purpose definition of stress, define it as any condition that triggers certain mental and physical needs on people.

Stress is defined as an individual's state of mind when encountering a harmful or threatening situation in an organization and work related stress is becoming an epidemic in almost every organization. Accurate diagnosis of various stressors is very vital in reducing or managing organizational stress. Stress can have different signs such as sleeplessness, aches and pains and anxiety about going to work. Nevertheless, there are some people that are able to stay in control of their workload without becoming worn out, irritable or depressed. These people are able to handle stress and can renew their energy and resources. "Life Styles or Life Orientations are the general orientations in one's life" [7].

The Health and Safety Executive (HSE) defines stress as an adverse reaction to excessive or extreme pressures or demands that may be placed upon individuals. Although there are different frameworks and theories to explain work-related stress, it can be seen as a psychological state that reflects the relationship between individuals and their work environment. The symptoms of job stress are divided to three mental, physical and behavioral groups. Also, different factors have been reported in this respect include cognitive and affective problems, depression, anxiety, feeling inadequate and isolation [8] for mental dimension; increased heartbeat, increased blood pressure, cardiac disease, digestive problems, sleep disturbances and headache for physical dimension [9]; and also absence from work [10], drug and alcohol consumption and smoking [11] for behavioral dimension.

Further, research results have shown that job stress has extensive effects on individual social and occupational life [1]. In other words, one of the most important consequences of job stress is related to mental health, life quality, family life and life satisfaction [12]. The results of Peterson's [13] study showed that workplace and workplace-related stresses can cause mental disorders in workers or it can accelerate their mental disorders which in turn lead to diseases, disability or failure.

There are many effective factors on job stress and life orientation (optimism and pessimism) and cognitive regulations are two of them.

Life orientation is an important construct in personality interpretation studies and it has been defined as positive evaluation of life and balance between positive and negative affection. Life orientation, in a holistic approach, is about the relationship of oneself with others and the community. This concept focuses on different aspects of personal growth such as physical, motor, spiritual, emotional, intellectual, social growth. Life orientation causes balanced communication between people and plays an important role in the improvement of the quality of 
life [14]. Also, experimental researches have shown that taking an optimist approach and not having pessimist orientation towards life help people's emotional adjustment, physical health and wellbeing to be increased [15]. For example, more optimism towards life, workplace and future working are related to regular blood pressure [16]; correct body performance [17]; more consistency and higher lifetime in chronic disease [18]. In this respect, research results have shown that optimism in the elderly people were accompanied with the highest level of general health, wellbeing, perceived mental health and the lowest level of physical pain [19].

Generally, researchers believe that positive life orientation (optimism) helps social relationships to be strengthened [20], which is an important factor for decreasing job stress. Also, studies have shown that psychological constructs such as optimism have profound influence on decreasing job stress such that this variable, with influence on mental viewpoint of a person, leads to job satisfaction and finally decrease his job stress [19] [20]. In fact, workers with these believes will have better and better work relationships (positive orientation) and such believes consequently decrease their job stress and increase their organizational performance. Such a view is against to people with negative orientation (pessimism) towards their work [21]. Such people have higher job stress compared to their co-workers.

On the other side, research has indicated that a conflict between different aspects of life orientation and personality characteristics of employees, such as their motives, preferences, needs, and values will lead to individual behavioral outcomes such as job dissatisfaction, low organizational commitment and engagement, low job performance, job stress and turnover [7] [22].

Cognitive emotion regulation is one of the effective factors on job stress. Emotion plays an important role in different aspects of life such as adjustment and tensioning events in workplace. Basically, emotion can be considered as biological reactions to situations that are evaluated as an important or challenging opportunity and these biological reactions are accompanied with our responses to environmental events [23]. Emotional experiences play central role in daily life, psychological health, motivational processes, suitable responding to stressful events and social revolution; and they influence on different actions of people. Although emotions (like fear, anger and hate) have biological bases, people still can influence on intensity, type and duration of their emotional experiences [24]. This process is referred to emotion regulation in psychological area.

The ability of emotion regulation of internal and external processes is responsible for controlling, evaluating and changing one's affective reactions in the way of actualization of goals [25]. Emotion regulation is a process in which people (intentional or unintentional) moderate their emotions in order to reach a desired outcome [26]. Previous studies have shown that inconsistent guidelines used for emotion regulation are effective in increase and endurance pathological states due to their conflict with self-regulation goals in emotional disturbance 
episodes [27]. This conflict may cause to distract attention from a long term self-regulation goal (like being healthy) and more focus on current emotional disturbance which finally will lead to looking for immediate satisfaction for escaping from this situation [28]. Bar-On [29] believes that emotional constructs are non-cognitive skills that increase person's abilities for successful coping with environmental pressures and distresses and lead to humanitarian and adaptable behaviors. Rothenberg and Gross [30] believe that emotion regulation includes a wide range of internal and external processes which are employed for revision, evaluation and moderation of emotional reactions. Also, it comprises a wide domain of cognitive, behavioral, emotional and physiological responses that are necessary for understanding emotional and behavioral correlations of stress and negative affective states [31]. Since it decreases stress level in coping with difficult situations, emotion regulation is itself the most important factor for predicting one's performance in workplace and it is the most powerful force for decreasing stress level [32].

The relationship between cognitive emotion regulation and workplace stress has gained more attention in the literature. Considering this fact that humans and specially employees live in a very stressful environment, the ability of controlling emotion is very important for them and it is essential for them to successfully regulate their emotions. Emotion-based behaviors, social interactions and communications are of particular importance at the workplace. However, these interactions at the workplace do not always mean oneself is allowed to exhibit and express all the emotions he/she may have. In fact, regulation of such experiences is required in the social context at work. Cognitive coping strategies often need more working experience for a considerable time. Perceived stress at work refers to the level of stress an individual experiences and it depends on several factors such as stressful events, coping strategies, and personality differences. Generally, stress can be a result of the interaction between persons and their environment. While trying to cope with a variety of stressful events, employees may not always to act upon their emotions. Conversely, they are required to control their emotions in such situations. Therefore, a stressful environment requires more emotion regulation skills [33] [34].

Considering the above mentioned issues, the aim of this study is to answer this question that is there any relationship between life orientation and job stress and between cognitive regulation and job stress?

\section{Methods}

\subsection{Population, Samples and Sampling Method}

This study was conducted within 2015-16 between employees working in Guilan Office of Education. On this basis, a sample of 100 employees (50 men and 50 women) was investigated through randomly selected samples based on a previously provided list from human resource management department of Guilan Education Office. The inclusion criteria were as follows: all respondents should 
be married and aged 30 - 60 years old; with metal and physical health and no self-reported record of clinical problems. All single employees or those with a record of clinical problems were excluded from the study.

\subsection{Population, Samples and Sampling Method}

Job Stress questionnaire (HSE): Job Stress questionnaire has been provided by Britain Health and Safety Executive and it entails 35 questions with a 5 point Likert type Scale. In this study, 8 questions were about demands, 6 questions about control, 3 questions about change, 4 questions about communication, 5 questions about role and 9 questions were about support. Marzabadi and Gholami Fesharaki [35] used this questionnaire in their open study which its Cronbach alpha was about 0.78 that indicates desired validity of this questionnaire. Also, Brookes et al. [36] and Kerr et al. [37] used the HSE tool in their study for psychometrically measuring of organizational performance. They reported that this questionnaire could provide a broad overview of sources and effective factors of work-related stress in organizations. However, they stated the possibility of the use of this tool and its use in different contexts and with different cultural and gender groups require more research.

Life Orientation Test (LOT): this questionnaire was constructed by Scheier and Carver in 1985 [38] for evaluation of dispositional optimism which consists of 8 items, 4 items for optimist character and 4 others for pessimist character. Respondents rate each item in a multi-level scale and state their level of agreement or disagreement with each term. This test was suitable in from the most psychometric aspects except this criticism that its optimist and pessimist terms not always had a high internal consistency. Several studies like Pulford [39], Scheier and Carver [38] and Scheier et al. [40] have shown that optimism and pessimism had good relationships with a wide range of related constructs such as self-esteem, hopelessness and neuroticism which indicate convergent validity of this questionnaire.

Cognitive emotion regulation questionnaire (CERQ): this questionnaire has been developed by Garnefski et al. [31] in Netherland and it is available in two English and Dutch versions. It has 36 items with strong empirical and theoretical bases and consists of 9 subscales. These subscales evaluate nine cognitive emotion regulation strategies include: self-blame; acceptance; rumination; positive refocusing; refocus on planning; positive reappraisal; catastrophizing and other-blame.

Self-blame is described as the thoughts which put the blame on yourself about what you have experienced in life events. By contrast, other-blame or blaming others refers to putting blame on others about what you have experienced. Rumination or focusing on thought refers to thinking about feelings associated with the negative life events. Positive refocusing is referred to the joyful and pleasant thinking instead of thinking about actual event. Acceptance refers to the thoughts that indicate thoughts about accepting what you have experienced or resigning yourself to what has happened. Catastrophizing is described as the 
thoughts that explicitly put more emphasize on the terror of an experience. Refocus on planning is described as the thoughts about taking suitable steps in order to handle the negative events in life. The last one is positive reappraisal that refers to think about creating and giving a positive meaning to the event with regards to personal growth [31] [33] [34] [41].

Persian version of cognitive emotion regulation questionnaire in Iranian culture has been normalized by Hasani [24]. Its test reliability was obtained through Cronbach alpha as $0.91,0.87$ and 0.93 respectively. In Iran, test validity was investigated through the correlation of total score with subscale scores which consists of a range from 0.40 to 0.68 with the average of 0.56 that they all were significant. Its reliability in Iranian culture was reported by Khatibi and Yousefi in 2003 [42] with a 0.82 Cronbach alpha coefficient for all cognitive scales.

All questionnaires were given to the respondents in printed versions and all of them were rated as follows: communication and demands were rated inversely (from 5 to 1 ) for more accuracy and validity to prevent from wrong deliberate report. Other items i.e. control, support, managers and supervisors' support, role and change were rated from 1 to 5 .

\section{Results and Discussion}

Table 1 shows the socio-demographic characteristics of respondents. Based on this study's results, the mean age of participants was 38.93 (standard deviation = 8.76). From education level, the majority of them had a B.Sc. degree. As it can be seen in Table 2, there is a negative significant correlation between life orientations, positive refocusing, refocus on planning and positive reappraisal with job stress while self-blame, acceptance, catastrophizing, rumination and other-blame had a positive significant correlation with job stress.

Furthermore, a stepwise statistical regression method was employed for allocating the role of life orientation and cognitive emotion regulation in prediction

Table 1. Socio-demographic characteristics of respondents $(n=100)$.

\begin{tabular}{|c|c|c|c|}
\hline \multirow{4}{*}{ Age (years) } & $30-40$ & \multicolumn{2}{|c|}{$30(30 \%)$} \\
\hline & $41-50$ & \multicolumn{2}{|c|}{$56(56 \%)$} \\
\hline & $51-60$ & \multicolumn{2}{|c|}{$11(11 \%)$} \\
\hline & $\geq 60$ & \multicolumn{2}{|c|}{$3(3 \%)$} \\
\hline Gender & \multicolumn{2}{|c|}{ Men: 50 (50\%) } & Women: $50(50 \%)$ \\
\hline Marital status & \multicolumn{3}{|c|}{ All married } \\
\hline \multirow{4}{*}{ Education level } & \multicolumn{3}{|c|}{ Associate degree: $4(4 \%)$} \\
\hline & \multicolumn{3}{|c|}{ Diploma: 3 (3\%) } \\
\hline & \multicolumn{3}{|c|}{ Bachelor's degree: 83 (83\%) } \\
\hline & \multicolumn{3}{|c|}{ Master's degree: $10(10 \%)$} \\
\hline \multirow{4}{*}{ Working experience (years) } & $\leq 5$ & 6 & $(6 \%)$ \\
\hline & $5-10$ & 80 & $(80 \%)$ \\
\hline & $10-20$ & 11 & $(11 \%)$ \\
\hline & $\geq 60$ & 3 & $(3 \%)$ \\
\hline
\end{tabular}


Table 2. Pearson correlation coefficients between research variables.

\begin{tabular}{cc}
\hline Variable & Job stress \\
\hline Life orientations & $-0.32^{* *}$ \\
Self-blame & $0.25^{\star}$ \\
Acceptance & 0.18 \\
Rumination & $0.36^{* *}$ \\
Positive refocusing & $-0.25^{*}$ \\
Refocus on planning & $-0.21^{*}$ \\
Positive reappraisal & $-0.28^{* *}$ \\
Taking attitudes & 0.17 \\
Catastrophizing & $0.39^{* *}$ \\
Other-blame & $0.25^{\star}$ \\
\hline
\end{tabular}

Table 3. Summary of regression model, variance analysis and statistical characteristics of life orientation and cognitive emotion regulation regressions.

\begin{tabular}{cccccccc}
\hline Model/job stress & $\mathrm{F}$ & $\mathrm{R}$ & $\mathrm{R}^{2}$ & $\mathrm{SE}$ & $\beta$ & $\mathrm{B}$ & $\mathrm{t}^{*}$ \\
\hline Catastrophizing & 15.23 & 0.39 & 0.15 & 1.08 & 0.153 & 0.195 & \\
Rumination & 11.47 & 0.45 & 0.20 & 0.88 & 0.119 & 0.146 & \\
Life orientation & 7.37 & 0.47 & 0.22 & 0.62 & -0.103 & 0.152 & \\
\hline
\end{tabular}

${ }^{*} \mathrm{P}<0.01$.

of job stress. For this purpose, life orientation and cognitive emotion regulation were separately introduced to regression equation as predictor variables that the results of regression analysis are presented in Table 3.

The results show that observation $\mathrm{F}$ is significant $(\mathrm{P}<0.01)$ and $22 \%$ of variances in job stress can be explained by catastrophizing, rumination and life orientation. Regression coefficients show that catastrophizing $(\beta=0.153)$, rumination $(\beta=0.119)$ and life orientation $(\beta=-0.103)$ can significantly explain job stress variances.

\section{Conclusions and Discussions}

Kerr et al. (2009) used a HSE MS questionnaire to measure employee's job stress. They found that Health and Safety Executive's (HSE) Management Standards (MS) are positively associated with job satisfaction and negatively associated with job-related anxiety and job-related depression.

With regards to the relationship between life orientation and job stress, $M$. Coetzee and M. de Villiers [22] found that sources of job stress are significantly related to individuals' career orientations. They found a statistically significant positive relationship between the career orientation variables and the sources of job stress. This result is consistent with our findings in this study and illustrates that people's dominant life orientations seem to be significantly related to their 
sources of job stress. This result suggests that providing favorable workplace conditions and implementing career support practices that satisfy the psychological needs in individuals' life orientation such as their motives and values can reduce employees' sources of job stress. As previous studies have shown too, life orientation is one of the predictors of general health and optimistic orientation toward life, and high life satisfaction is considered as a protected variable for physical and psychological health too [7] [14] [43] [44].

Furthermore, taking positive and negative life orientation (optimism and pessimism) has been proved to be negatively and positively related to depression and anxiety [42] [43] [44] [45]. In this regards, Gustems-Carnicer et al. [43] in their study about the relationship between life orientation, psychological well-being and academic progress in college students found that depressive symptoms and psychological distress are caused by experiencing depression and anxiety is negatively related to optimism and positively with academic progress at university. One explanation may be that subjective well-being and optimism are closely linked. Also, they found a gender difference in the relationship between optimism and academic progress. They investigated the differences between men and women in academic progress and concluded that excessive self-confidence in men is linked to less academic progress, while a certain degree of optimism was necessary in women for academic progress.

This study also investigated the role of cognitive emotion regulation on job stress and we found a both positive and negative significant relationship with different cognitive emotion regulation job stress coping strategies. This result is consistent with Demirtas et al. [33]; Extremera and Rey [34]; Garnefski et al. [23] [31] since they found that cognitive emotion regulation impacted individual's job stress through shaping work related and non-work related social supports. The results of this study are consistent with the literature findings. Demirtas et al. [33] investigated the relationship between cognitive emotion regulation and job stress and found that social support is another important aspect that has positive and moderating effects on reducing the stress of employees.

Our results showed that there is an important relationship between cognitive emotion regulation and stress. Stress is an important epidemic issue for employees in any organization. Lower levels of stress often result in higher job satisfaction and more satisfied employees which in turn lead to a better work environment with better outcomes. There are several ways that organizations can achieve lower levels of stress in the workplace. One method is to provide better work conditions that will limit stressors. However, considering this fact that work life may be full of stressors, one way to cope such situations could be the ability to control and regulate emotions for the purpose of having a productive work environment.

Therefore, it is necessary for employees to have the ability of two regulating emotions such that they could manage their emotions and consequently their work-related stress. In this respect, organizations should select employees with 
who are able to manage and regulate their emotions in the recruitment stage. Furthermore, programs focused on employee development can enhance such skills through training programs and workshops (Demirtas et al. [33]).

Shahba et al. [46] investigated the effect of cognitive emotion regulation strategies on job satisfaction. Their results showed that the adjusted cognitive emotion regulation as stress coping strategies will lead to increase in job satisfaction of employees while unadjusted cognitive emotion regulation strategies will reduce their' job satisfaction. Moreover, they found that rumination has no significant effect on job satisfaction. Also, their results showed that, in addition to reducing job satisfaction of employees, unadjusted cognitive emotion regulation strategies will increase depression and anxiety [23], such that people who with unadjusted emotion regulation strategies reported lower job satisfaction when facing with negative events.

Also, with regards to cognitive emotion regulation strategies, Mihalca and Tarnavska [47] showed that catastrophizing and acceptance could significantly predict social functioning problems, while catastrophizing, refocus on planning and self-blame could predict associated distress.

Gerin et al. [48] focused on rumination as a Mediator of Chronic Stress. They showed that stressors can emerge both in responses to stressors present in one's environment and to mental representations of other stressors. They found that, experiencing any given stressor may be brief itself but a stressor often results in constellation of negative emotions that form a mental representation of that given stressor. They concluded that ruminating about such mental representation of a given stressful event can cause autonomic response similar to that observed in response to the actual incident, and may persist long after the event itself has happened. Thus, they suggested that rumination helps explain how chronic stress increasingly causes activation of one's stress-mediating physiological systems over time.

Duarte et al. [49] focused on gender differences about cognitive emotion regulation strategies. They found a moderating effect of gender in the relationship between positive reappraisal and depressive symptoms, which indicates the importance of increasing positive reappraisal when facing negative life events, such as workplace related events, especially for women. They also found that women also tend to use less adaptive cognitive emotion regulation strategies (rumination and self-blame) than men. Women really tend to use less this strategy than men and the use of positive reappraisal often causes a more significant decrease of depressive symptoms level for women.

Garland et al. [50] found that positive reappraisal mediates the stress-reductive effects of mindfulness. They showed that there is an upward spiral between dispositional mindfulness and positive reappraisal which in turn has significant effects on stress reduction. Their findings indicate that increased dispositional mindfulness can increase positive reappraisal, and conversely. There seems to be a mutual interaction between positive reappraisal and dispositional mindfulness 
as they reciprocally can enhance one another.

Querstret and Cropley [51] investigated work-related affective rumination and concluded that it is more detrimental to an individual's ability of recovering from work than problem-solving pondering. They suggest that the type of work-related rumination is more important than rumination per se.

Stress in a non-specific reaction that is created under influence of different stressful events in organisms and threaten individuals' physical and psychological wellbeing [52]. Job is one of the most important sources of stress in each individual life. Today, job stress has become a prevalent and cost-consuming problem in workplace such that United Nation Organization named it $20^{\text {th }}$ century disease and World Health Organization reported it as an epidemic problem [53]. Stress is an affective, cognitive, behavioral and mental reaction to harmful aspects of work and workplace [41] [54]. Generally, job stress can be considered as a response to work-related pressures that happens when expectation from someone is beyond his capability and authorization [46] [52]. In this respect, our findings indicated that there is a significant relationship between life orientation and job stress. In other words, optimist employees with positive life orientation have the lowest job stress. In fact, a positive view towards life will lead to decrease in daily stress which significantly will decrease job stresses too. When coping with daily problems and even job related problems, employees with reasonable and positive attitude towards life have the lowest stress level due to their optimist thoughts.

In another dimension, emotion regulation has an important role in decreasing employees' job stress. The way of responding to unpleasant life events is different among people; some of them can easily manage their negative emotions and even replace them with positive ones in an excellent level. Such people, when coping with unpleasant event in their life, often try to take the best decision and believe that conditions could be worse; think about better issues, accept realities, think about the underlying events that led to this problem and try to solve that problem; or they think about good things and try to eliminate metal pressures. Such people can manage their emotions when coping with job stresses and report that lowest level of job stresses too.

This study investigated the relationship between life orientation and cognitive emotion regulation with job stress. The results of this study indicate that job stress has a significant relationship with life orientation, self-blame, rumination, positive refocusing, positive refocusing on program, positive reappraisal, catastrophizing and other-blame. Furthermore, life orientation and cognitive regulation could explain variances in respondents' job stress. This means more positive life orientation and subsequent decrease of emotion-regulation-related disorders can decrease job stress.

\section{References}

[1] Obradović, J. and Čudina-Obradović, M. (2011) Work Stress and Marital Quality in Dual Earner: A Test of Three Mediation Models. Društvena istraživanja: Časopis za 
opća društvena pitanja, 22, 673-691. https://doi.org/10.5559/di.22.4.06

[2] Baloban, J. and Črpić, G. (2000) Bitnevrednotezauspješanbrak u Hrvatskoj (Essential Values for a Successful Marriage in Croatia). Bogoslovskasmotra, 70, 313-341.

[3] Molai, M., Mohammadi, A., Habibi, A., Zamanzadh, V., Molavi, P. and Mozaffari, N. (2011) Evaluation of Some Factors in Job Stress and Working Women in Ardebil 2009. Journal of Ardabil University of Medical Sciences, 11, 76-85.

[4] Laird, M.D., Perryman, A.A., Hochwarter, W.A., Ferris, G.R. and Zinko, R. (2009) The Moderating Effects of Personal Reputation on Accountability-Strain Relationship. Journal of Occupational Health Psychology, 14, 70-83. https://doi.org/10.1037/a0012567

[5] Kahn, R.L. and Byosiere, P. (1992) Stress in Organizations. In: Dunnete, M.D. and Hough, L.M., Eds., Handbook of Industrial and Organizational Psychology, 2nd Edition, Consulting Psychologist Press, Palo Alto, CA, Vol. 3, 571-650.

[6] Dipboye, R.L., Smith, C.S. and Howell, W. (1994) Understanding Industrial and Organizational Psychology: An Integrated Approach. Harcourt Brace College Publishers, Fort Worth.

[7] Mukherjee, D. (2012) Facilitating Productive Work Life with Respect to Life-Orientation, Gender and Occupational Stress. Journal of Organisation \& Human Behaviour, 1, 12-17.

[8] Spooner-Lane, R., Ed. (2004) The Influence of Work Stress and Work Support on Burnout in Public Hospital Nurses. Queensland University of Technology, Brisbane.

[9] Aghilinejad, M., Mohammadi, S., Afkari, M. and Abbaszade Dizaji, R. (2007) Surveying the Association between Occupational Stress and Mental Health, Personality and Life Stressful Events in Tehran Police Officers. Research in Medicine, 31, 355-360.

[10] Hoogendoorn, W.E., Bongers, P.M. and de Vet, H.C. (2002) High Physical Work Load and Low Job Satisfaction Increase the Risk of Sickness Absence Due to Low Back Pain: Results of a Prospective Cohort Study. Occupational \& Environmental Medicine, 59, 323-328. https://doi.org/10.1136/oem.59.5.323

[11] Seward, J.P. (2004) Occupational Stress. In: LaDou, J., Ed., Current Occupational \& Environmental Medicine, 3rd Edition, MC Grow Hill, New York, 603-618.

[12] Bolger, N., DeLongis, A., Kessler, R. and Wethington, E. (1989) The Contagion of Stress across Multiple Roles. Journal of Marriage and Family, 51, 175-183. https://doi.org/10.2307/352378

[13] Peterson, D.K. (2003) The Relationship between Ethical Pressure, Relativistic Moral Beliefs and Organizational Commitment. Journal of Managerial Psychology, 18, 557-572. https://doi.org/10.1108/02683940310494386

[14] Aghaei, A., Khayyamnekouei, Z. and Yousefy, A. (2013) General Health Prediction Based on Life Orientation, Quality of Life, Life Satisfaction and Age. Procedia-Social and Behavioral Sciences, 84, 569-573. https://doi.org/10.1016/j.sbspro.2013.06.605

[15] Rasmussen, H.N., Scheier, M.F. and Greenhouse, J.B. (2009) Optimism and Physical Health: A Meta-Analytic Review. Annals of Behavioral Medicine, 37, 239-256. https://doi.org/10.1007/s12160-009-9111-x

[16] Raikkonen, K., Matthews, K.A., Flory, J.D., Owens, J.F. and Gump, B.B. (1999) Effects of Optimism, Pessimism, and Trait Anxiety on Ambulatory Blood Pressure and Mood during Everyday Life. Journal of Personality and Social Psychology, 76, 104-113. https://doi.org/10.1037/0022-3514.76.1.104 
[17] Kubzansky, L.D., Wright, R.J., Cohen, S., Weiss, S., Rosner, B. and Sparrow, D. (2002) Breathing Easy: A Prospective Study of Optimism and Pulmonary Function in the Normative Aging Study. Annals of Behavioral Medicine, 24, 345-353. https://doi.org/10.1207/S15324796ABM2404_11

[18] Allison, P.J., Guichard, C., Fung, K. and Gilain, L. (2003) Dispositional Optimism Predicts Survival Status 1 Year after Diagnosis in Head and Neck Cancer Patients. Journal of Clinical Oncology, 21, 543-548. https://doi.org/10.1200/JCO.2003.10.092

[19] Achat, H., Kawachi, I., Spiro, A., III, DeMolles, D.A. and Sparrow, D. (2000) Optimism and Depression as Predictors of Physical and Mental Health Functioning: The Normative Aging Study. Annals of Behavioral Medicine, 22, 127-130. https://doi.org/10.1007/BF02895776

[20] Machaty, A. (2013) Dispositional Optimism and Marital Adjustment. Theses and Dissertations, Family Sciences, Paper 7. http://uknowledge.uky.edu/hes_etds/7.

[21] Lavner, J., Karney, B. and Bradbury, T (2013) Newlyweds' Optimistic Forecasts of their Marriage: For Better or for Worse? Journal of Family Psychology, 27, 531-540. https://doi.org/10.1037/a0033423

[22] Coetzee, M. and de Villiers, M. (2010) Sources of Job Stress, Work Engagement and Career Orientations of Employees in a South African Financial Institution. Southern African Business Review, 14, 27-58.

[23] Gavnefski, N., Kraaij, V. and Spinhoven, P. (2001) Negative Life Events, Cognitive Emotion Regulation and Emotional Problems. Personality and Individual Differences, 30, 1311-1327. https://doi.org/10.1016/S0191-8869(00)00113-6

[24] Hasani J. (2010) The Psychometric Properties of the Cognitive Emotion Regulation Questionnaire (CERQ). Journal of Clinical Psychology, 2, 73-84.

[25] Thompson, R.A. (1991) Emotional Regulation and Emotional Development. EducPsychol Rev. 3: 269. https://doi.org/10.1007/BF01319934

[26] Aldao, A., Nolen-Hoeksema, S. and Schweizer, S. (2010) Emotion-Regulation Strategies across Psychopathology: A Meta-Analytic Review. Clinical Psychology Review, 30, 217-137. https://doi.org/10.1016/j.cpr.2009.11.004

[27] Moore, S.A., Zoellner, L.A. and Mollenholdt, N. (2008) Are Expressive Suppression and Cognitive Reappraisal Associated with Stress-Related Symptoms? Behavior Research and Therapy, 46, 993-1000. https://doi.org/10.1016/j.brat.2008.05.001

[28] Tice, D.M., Bratslavsky, E. and Baumeister, R.F. (2001) Emotional Distress Regulation Takes Precedence Over Impulse Control: If You Feel Bad, Do It! Journal of Personality and Social Psychology, 80, 53-67. https://doi.org/10.1037/0022-3514.80.1.53

[29] Bar-On, R. (2006) The Bar-On Model of Emotional-Social Intelligence (ESI). Psicothema, 18, 13-25.

[30] Rottenberg, J. and Gross, J.J. (2003) When Emotion Goes Wrong: Realizing the Promise of Affective Science. Clinical Psychology Science and Practice, 10, 227-232. https://doi.org/10.1093/clipsy.bpg012

[31] Garnefski, N., Van Den Kommer, T., Kraaij, V., Teerds, J., Legerstee, J. and Onstein, E. (2002) The Relationship between Cognitive Emotion Regulation Strategies and Emotional Problems: Comparison between a Clinical and a Non-Clinical Sample, European Journal of Personality, 16, 403-420. https://doi.org/10.1002/per.458

[32] Kelly, Z.L. (2004) Experiencing Job Burnout: Their Roles of Positive and Negative Traits and States. Journal of Applied Social Psychology, 34, 887-991. https://doi.org/10.1111/j.1559-1816.2004.tb02576.x 
[33] Demirtas, O., Ozdevecioglu, M. and Capar, N. (2015) The Relationship between Cognitive Emotion Regulation and Job Stress: Moderating Role of Social Support Asian Social Science; 11, 168-173.

[34] Extremera, N. and Rey, L. (2014) Health-Related Quality of Life and Cognitive Emotion Regulation Strategies in the Unemployed: A Cross-Sectional Survey. BioMed Central, 12, 172-180.

[35] Marzabadi, E. and Gholami Fesharaki, M. (2010) The Investigation of Validity and Reliability of HSE Questionnaire, Journal of Behavioral Science, 14, 291-298.

[36] Brookes, K., Limbert, C., Deacy, C., O’Reilly, A., Scott, S. and Thirlaway, K. (2013) Systematic Review: Work-Related Stress and the HSE Management Standards. Occupational Medicine, 63, 463-472. https://doi.org/10.1093/occmed/kqt078

[37] Kerr, R., McHugh, M. and McCrory, M. (2009) HSE Management Standards and Stress-Related Work Outcomes. Occupational Medicine, 59, 574-579. https://doi.org/10.1093/occmed/kqp146

[38] Scheier, M.F. and Carver, C.S. (1985) Optimism, Coping, and Health: Assessment and Implications of Generalized Outcome Expectancies. Health Psychology, 4, 219-247. https://doi.org/10.1037/0278-6133.4.3.219

[39] Pulford, B.D. (2009) Is Luck on My Side? Optimism, Pessimism, and Ambiguity Aversion. Quarterly Journal of Experimental Psychology, 62, 1079-1087. https://doi.org/10.1080/17470210802592113

[40] Scheier, M.F., Carver, C.S. and Kus, L.A. (1994) Effects of Good versus Bad Mood and Optimistic versus Pessimistic Outlook on Social Acceptance versus Rejection. Journal of Social and Clinical Psychology, 13, 138-151. https://doi.org/10.1521/jscp.1994.13.2.138

[41] Garnefski, N., Pannebakker, N., Ruchlewska, A. and Kraaij, V. (2003) Relationships between Cognitive Coping Strategies, Personality Traits and Symptoms of Depression. Gedragen Gezondheid, 31, 250-261.

[42] Khatibi, M. and Yousefi, F. (2003) Cognition and Emotion: The Cognitive Regulation of Emotions: A Review. The International Journal of Indian Psychology, 2, $15-24$.

[43] Gustems-Carnicer, J. Calderón, C. and Santacana, F. (2017) Psychometric Properties of the Life Orientation Test (LOT-R) and Its Relationship with Psychological Well-Being and Academic Progress in College Students. Revista Latinoamericana de Psicología, 49, 19-27. https://doi.org/10.1016/j.rlp.2016.05.001

[44] White, B.P. and Ma, A. (2014) Relationships among Occupation/Activity Patterns, Health and Stress Perceptions, and Life Orientation in Well Adults. The Open Journal of Occupational Therapy, 2, 1-17.

[45] Rathore, S., Kumar, A. and Gautam, A. (2015) Life Satisfaction and Life Orientation as predictors of Psychological Well Being. The International Journal of Indian Psychology, 3, 20-27.

[46] Shahba, S., Alvani, S.M., Zahedi, S.A. and Memarzadeh, G. (2014) An Investigation on the Effect of Cognitive Emotion Regulation Strategies on Job Satisfaction. Management Science Letters, 4, 1315-1324. https://doi.org/10.5267/j.msl.2014.4.010

[47] Mihalca, A.M. and Tarnavska, Y. (2012) Cognitive Emotion Regulation Strategies and Social Functioning in Adolescents. Procedia-Social and Behavioral Sciences, 82, 574-579. https://doi.org/10.1016/j.sbspro.2013.06.312

[48] Gerin, W., Zawadzki, M.J., Brosschot, J.E., Thayer, J.F., Christenfeld, N.J., Campbell, 
T.S. and Smyth, J.M. (2012) Rumination as a Mediator of Chronic Stress Effects on Hypertension: A Causal Model. International Journal of Hypertension, 2012, Article ID: 453465. https://doi.org/10.1155/2012/453465

[49] Duarte, A.C., Matos, A.P. and Marques, C. (2015) Cognitive Emotion Regulation Strategies and Depressive Symptoms: Gender's Moderating Effect. Procedia-Social and Behavioral Sciences, 165, 275-283. https://doi.org/10.1016/j.sbspro.2014.12.632

[50] Garland, E.L., Gaylord, S.A. and Fredrickson, B.L. (2011) Positive Reappraisal Mediates the Stress-Reductive Effects of Mindfulness: An Upward Spiral Process. Mindfulness, 2, 59-67. https://doi.org/10.1007/s12671-011-0043-8

[51] Querstret, D. and Cropley, M. (2012) Exploring the Relationship between Work-Related Rumination, Sleep Quality and Work-Related Fatigue. Journal of Occupational Health Psychology, 17, 341-353. https://doi.org/10.1037/a0028552

[52] Ghanei, R., Valeei, S., Rezaei, M. and Rezaei, K. (2013) The Relationship between Personal Traits and Job Stress among Nurses. Iranian Journal of Psychiatric Nursing, 1, 27-34.

[53] Milutinovic, D., Golubovic, B., Brkic, N. and Prokes, B. (2012) Professional Stress and Health among Critical Care Nurses in Serbia. Archives of Industrial Hygiene and Toxicology, 63, 171-180. https://doi.org/10.2478/10004-1254-63-2012-2140

[54] Antigoni, F., Pediaditaki, O. and Dimitrios, T. (2011) Nursing Staff under Heavy Stress: Focus on Greece-A Critical Review. International Journal of Caring Sciences, 4,11 . 